\title{
Formulation and evaluation of Mefenamic acid solid dispersions
}

Gomathi Murugan*, Jothimanivannan Chennakesavalu, Kalaiselvi Chinnamuthu, Soundharya Kaveri

Department of Pharmaceutics, SS Institute of Pharmacy, Sankari, Salem Tamilnadu, India

Received: 06-08-2021 / Revised Accepted: 28-08-2021 / Published: 01-09-2021

\begin{abstract}
The main objective of this study was to prepare and evaluate solid dispersion of Mefenamic acid, to enhance the dissolution rate, solubility \& bioavailability. Mefenamic acid solid dispersion were prepared using Poly vinyl Pyrrolidone (PVP K 30) and Poly Ethylene Glycol (PEG 4000) as hydrophilic carriers by solvent evaporation and kneading techniques. FTIR studies showed that there was no interaction between the drug and polymer. The prepared Solid dispersion KM3(1:3) using PVP K30 showed minimal wetting time of 14 seconds compared with the other formulations. In vitro release studies in Phosphate buffer $\mathrm{pH}$ of 7.4 revealed that the solid dispersions prepared by kneading method showed faster drug release compared with solvent evaporation method. So, the dissolution profile of solid dispersion containing PVP K30 (1:3) by kneading method was selected as the best formulation because of its faster drug release among all formulations. The development of solid dispersion of Mefenamic acid could be a promising approach to enhance its dissolution rate, solubility and bioavailability.
\end{abstract}

Keywords: Solid dispersion, Mefenamic acid, PVP K30, PEG4000

\section{INTRODUCTION}

Oral administration is the most convenient, widely utilized, and preferred route of drug delivery for systemic action. Poor aqueous solubility is one of the major hurdles in the development of new drugs into oral dosage forms, since dissolution is the first step in the absorption of drugs. The solubility and dissolution behaviour of a drug is key determinant to its oral bioavailability. An improvement of oral bioavailability of poorly water-soluble drugs remains one of the most challenging aspects of drug development. [1,2] Mefenamic acid, an anthranilic acid derivative, is used to treat symptoms of pain, rheumatoid arthritis and dysmenorrhea. Mefenamic acid binds the prostaglandin synthetase receptors COX-1 and COX-2, inhibiting the action of prostaglandin synthetase. Its half-life is 2 hours. It belongs to BCS class II, having low solubility \& high permeability. Due to the poor solubility of drug, the dissolution is reduced and hence it suffers from

Address for Correspondence: Gomathi Murugan, Department of Pharmaceutics, SS Institute of Pharmacy, Sankari, Salem, Tamilnadu, India; E-mail: gomathidurga24@gmail.com

How to Cite this Article: Gomathi Murugan, Jothimanivannan Chennakesavalu, Kalaiselvi Chinnamuthu, Soundharya Kaveri. Formulation and evaluation of Mefenamic acid solid dispersions. World J Pharm Sci 2021; 9(9): 160-169.

This is an open access article distributed under the terms of the Creative Commons Attribution-NonCommercialShareAlike 4.0 International License, which allows adapt, share and build upon the work non-commercially, as long as the author is credited and the new creations are licensed under the identical terms. (cc) EY-NC-SA 
oral bioavailability problems. Therefore, solid dispersion technologies are particularly promising for improving the oral absorption and bioavailability of BCS class II drugs [3]. Solid dispersion technique is widely used to increase the solubility and dissolution characteristics of drugs with poor solubility. Solid dispersions can be prepared using hydrophilic carriers Polyethylene glycol 4000 \& Polyvinyl Pyrrolidone K 30 by Solvent evaporation and Kneading methods. The ultimate aim is to enhance the wettability, dissolution rate and solubility of Mefenamic acid.

\section{MATERIALS AND METHODS}

Mefenamic acid was a gift sample from Microlabs, Bangalore. PVP K 30, PEG 4000 \& Methanol were obtained from Loba Chemie, Mumbai. All other chemicals used were of analytical grade.

Calibration of Mefenamic acid: A standard curve was prepared with different concentration (2 to $12 \mu \mathrm{g} / \mathrm{ml}$ ) using $\mathrm{pH} 7.4$ phosphate buffer solution. The absorbance of these solutions were measured at $\lambda$ max by UV- spectrophotometer. The calibration graph was drawn by taking the concentration on $\mathrm{X}$ axis and respective absorbance in $\mathrm{Y}$ axis, to get a straight line as per like Beer's law. This standard curve was used to estimate the concentration of the drug release from the formulation during the in vitro dissolution studies. [4]

Fourier Transform Infra-red spectroscopic studies (FTIR): FTIR Spectroscopic study was carried out to check the compatibility between drug and polymer. The spectrum of Mefenamic acid (pure drug) and physical mixtures were recorded using Fourier transform infrared spectrometer (Spectrum RX-1 Perkin-Elmer, German). Samples were prepared using $\mathrm{KBr}$ (Spectroscopic grade) discs by means of hydraulic pellet press at a pressure of five tons for 30 seconds at a resolution of $4 \mathrm{~cm}^{-1}[4,5]$

Preparation of Solid dispersion: Solid dispersions were prepared by using different carriers PEG 4000 \& PVP K 30 in different drug: carrier ratios of $1: 1$, $1: 2,1: 3$ by solvent evaporation and Kneading methods.

The various compositions of drug and hydrophilic carriers were shown in Table 1.

\section{Kneading method}

A mixture of drug (Mefenamic acid) and carriers (PVP K30 and PEG 4000) in different ratios (1: 1, $1: 2 \& 1: 3$ ) were wetted with solvent (methanol) and water (1: 1 ratio) and kneaded thoroughly for 30 minutes in a glass mortar. The paste formed was dried under room temperature for 24 hours. Dried powder was scrapped, crushed, pulverized and passed through sieve No. 40 and stored in a desiccator. [6,7]

\section{Solvent evaporation method}

Mefenamic acid solid dispersion was prepared by solvent evaporation method using carriers PVP K30 \& PEG 4000, in proportions viz., (1: 1, 1: 2 \& 1:3). Dissolve the drug and carrier using methanol in a china dish and the mixture is heated until the solvent gets evaporated and clear film of drug and carrier was obtained. The resultant solid dispersion was scraped with a spatula. Solid dispersions were pulverized in a mortar and pestle and passed through sieve No.40 before packing in an airtight container. [8,9]

Micromeritic studies: All the formulations were evaluated for bulk density, tapped density, angle of repose, compressibility index \& Hausner ratio.

Bulk density [10]: It was measured by pouring the solid dispersion into a measuring cylinder and initial weight was noted. This initial volume was called the bulk volume.

mass of solid dispersion $(\mathrm{gm})$

$$
\text { Bulk density = - - bulk volume }(\mathrm{ml})
$$

Tapped density [10]: It was determined by placing a graduated cylinder, containing a known mass of solid dispersion. The cylinder was allowed to fall under its own weight onto a hard surface from the height of $10 \mathrm{~cm}$ at 2 second intervals. The tapping was continued until no further change in volume was noted.

mass of solid dispersion (gm)

$$
\begin{gathered}
\text { Tapped density }=\text { - } \text { Tapped volume }(\mathrm{ml})
\end{gathered}
$$

Angle of Repose [11]: The angle of repose was determined using funnel method. Funnel that can be fit vertically with stand at $2 \mathrm{~cm}$.height. Appropriate quantity of solid dispersion was poured into funnel and a conical pile height (h) was obtained. Radius of the heap (r) was measured and the angle of repose $(\boldsymbol{\theta})$, calculated using the formula,

$$
\begin{aligned}
& \tan ^{\theta}=\mathbf{h} / \mathbf{r} \\
& \theta=\tan ^{-1} \mathrm{~h} / \mathrm{r} \\
& \mathrm{h}=\text { height of pile }(\mathrm{cm}) \text {. } \\
& \mathrm{r}=\text { radius of pile }(\mathrm{cm}) \text {. }
\end{aligned}
$$

Carr's index (or) \% compressibility [12]: Carr's index, also known as \% compressibility. It indicates the powder flow properties.

Tapped density - Bullk density

Carr' s index= ------------- x 100
Tapped density 
Hausner Ratio [12]: Hausner ratio, an indirect index of ease of powder flow. It is calculated by the following formula,

Tapped density
Hausner ratio $=$----------
Bulk density
Lower Hausner ratio $(>1.25) \quad$ indicates good
flow. Higher Hausner ratio $(<1.5)$ indicates poor
flow. 1.25-1.5 indicates normally improves flow.

Determination of percentage practical yield: $[13,14]$ : The $\%$ practical yield of all the prepared formulations were found out using the formula,

Practical mass (solid dispersion)

Practical yield = ---------------------------- X 100

Theoretical mass (drug + carrier)

Determination of drug content: Solid dispersions equivalent to $10 \mathrm{mg}$ of Mefenamic acid were weighed accurately and dissolved in $10 \mathrm{ml}$ of methanol, diluted with phosphate buffer $\mathrm{pH} 7.4$ at $\lambda \max$ by UV-spectrophotometer. $[15,16]$

Sample absorbance

$$
\% \text { drug content }=\text { - }
$$

Determination of wettability: Mefenamic acid solid dispersions were placed in a sintered glass funnel plunging into beaker containing water such that the surface of water in the beaker remains at the same level of formulation in the funnel. Methylene blue powder, layered uniformly on the surface of various formulations in the funnel and the time required for wetting methylene blue powder was measured. [17]

In vitro dissolution studies: Dissolution study was carried out by using USP rotating basket apparatus (Type I) for 1 hour, with a stirring rate of $100 \mathrm{rpm}$. Phosphate buffer $\mathrm{pH}$ 7.4, used as dissolution medium $(900 \mathrm{ml})$ and temperature was maintained at $37 \pm 0.5^{\circ} \mathrm{C}$. Solid dispersions equivalent to 100 $\mathrm{mg}$ of Mefenamic acid was filled in hard gelatin capsules used for dissolution studies. Samples $(5 \mathrm{ml})$ were collected at regular interval of time $(10,20,30,40,50 \& 60 \mathrm{~min})$. The same volume of fresh buffer solution was replaced into the dissolution jar after each sample with drawl. Similarly, dissolution test was conducted for the physical mixtures and pure drug. The absorbance of the samples was measured using Ultraviolet (UV) spectrophotometer at $\lambda_{\max }$ after suitable dilution using appropriate blank. $[18,19]$

Solubility Studies [20]: Saturation solubility study was determined by using shake flask method. The solubility of Mefenamic acid as pure drug, physical mixture and solid dispersion were determined in phosphate buffer $\mathrm{pH}$ 7.4. Excess quantities of drug, physical mixture and solid dispersions were added in $25 \mathrm{ml}$ of $\mathrm{pH} 7.4$ buffer in $250 \mathrm{ml}$ flasks which are then incubated in rotary flask shaker for 72 hours at $37^{\circ} \mathrm{C}$ at $50 \mathrm{rpm}$. Absorbance of these resulting solutions were measured by UV spectrophotometer at $\lambda_{\max }$

\section{RESULTS AND DISCUSSION}

The $\lambda_{\max }$ of Mefenamic acid was determined by scanning the $10 \mu \mathrm{g} / \mathrm{ml}$ of the drug solution in phosphate buffer solution $\mathrm{pH} 7.4$ by UVspectrophotometer. It showed the $\lambda_{\max }$ of $279 \mathrm{~nm}$ in phosphate buffer solution $\mathrm{pH} 7.4$. Mefenamic acid obeys the Beer's law within the concentration range of $2-12 \mu \mathrm{g} / \mathrm{ml}$ was shown in Figure 1. Linear correlation coefficient obtained was $r^{2}=0.9999$ for calibration of Mefenamic acid.

FTIR spectrum of Pure Mefenamic acid showed sharp characteristic peaks at 3291.28, 2928.38, 1832.14, 1707.78, $762.43 \mathrm{~cm}^{-1}$. All the above characteristic peaks appear in the spectra of all binary systems were within the same wave number. FTIR studies revealed that there was no interaction between the drug and polymeric carriers and shown in Figure 2(a-c). Twelve formulations were prepared using carriers (PVP K 30 \& PEG 4000) in different ratios by two different (Solvent evaporation and Kneading) methods were shown in Table 1.

All the prepared formulations were evaluated for bulk density, tapped density, angle of repose, compressibility index \& Hausner ratio and the results were shown in Table 2. The results of $\%$ practical yield indicated that there was no considerable loss in the yield during the process \& the drug content in the range of $95.1 \%$ to $98.4 \%$ indicating the uniform distribution of drug in the formulations were depicted in Table 3. Among all the formulations minimal mean wetting time (14 seconds) was observed for the dispersion containing PVP K30 prepared by kneading method. The results obtained for the wettability study was shown in Figure 3.

In vitro dissolution studies showed that there was marked increase in the dissolution rate of Mefenamic acid from all the solid dispersions when compared to physical mixture and pure drug. From the in vitro drug release profile, it could be seen that formulation KM3 containing PVP K30 (1:3 ratio of drug: carrier) showed higher dissolution rate $93.43 \%$ at 1 hour, so it was considered as the overall best formulation.

From the results, it was observed that, among the two carriers, PVP K30 was found to have greater release rate than PEG 4000. 


\section{PVP K30 > PEG 4000}

The increase in dissolution rate of the drug in both, the physical mixtures and solid dispersions were reported because of the enhanced wettability and hydrophilic nature of the carriers in the formulations. The best formulation was selected based on the results obtained from the wettability and in vitro release studies.

In vitro release studies revealed that the solid dispersions prepared using PVP K 30 by Kneading method showed faster drug release compared with Solvent evaporation method. KM3 (1:3) was selected as the best formulation because of its faster wetting and dissolution rate among all formulations. The results were shown in Figure 4(a-f).

The solubility study was conducted with pure drug, physical mixture (1:3, drug:PVP K 30) and selected best formulation (KM3) in phosphate buffer $\mathrm{pH}$ 7.4 as shown in Figure 5. It was observed that the solid dispersion $(1.723 \mu \mathrm{g} / \mathrm{ml})$ (KM3) has highest solubility compared to pure drug $(0.1987 \mu \mathrm{g} / \mathrm{ml})$ and physical mixture $(1.412 \mu \mathrm{g} / \mathrm{ml})$ in phosphate buffer $\mathrm{pH}$ 7.4.

Mefenamic acid solid dispersions showed maximum drug release when compared to the pure drug and physicalmixture. Enhancement of both, dissolution rate and solubility of Mefenamic acid in solid dispersions and physical mixtures were reported because of the increased wettability and hydrophilic nature of the carriers used.

\section{CONCLUSION}

It was concluded that the kneading and solvent evaporation methods were useful methods for the successful enhancement of solubility of poorly water-soluble drug Mefenamic acid with faster dissolution rate. The rate of wetting, dissolution and solubility of Mefenamic acid from solid dispersions were found to be significantly higher than pure drug. Thus, solid dispersions of Mefenamic acid with increased dissolution profile was successfully developed using PVP K 30 as carrier.

\section{ACKNOWLEDGEMENT}

The authors would like to express their sincere thanks to the management and Principal of SS Institute of Pharmacy for their encouragement and providing necessary facilities in carryout the research work.

TABLE 1. COMPOSITION OF MEFENAMIC ACID \& CARRIERS FOR SOLID DISPERSIONS

\begin{tabular}{|l|l|l|l|l|}
\hline S. No & $\begin{array}{l}\text { Formula } \\
\text { code }\end{array}$ & Composition & $\begin{array}{l}\text { Ratio } \\
\text { Drug: } \\
\text { polymer }\end{array}$ & Method \\
\hline 1. & SEM1 & Mefenamic acid: PVP K30 & $1: 1$ & Solvent evaporation method \\
2. & SEM2 & Mefenamic acid: PVP K30 & $1: 2$ & Solvent evaporation method \\
3. & SEM3 & Mefenamic acid: PVP K30 & $1: 3$ & Solvent evaporation method \\
4. & SEM4 & Mefenamic acid: PEG 4000 & $1: 1$ & Solvent evaporation method \\
5. & SEM5 & Mefenamic acid: PEG 4000 & $1: 2$ & Solvent evaporation method \\
6. & SEM6 & Mefenamic acid: PEG 4000 & $1: 3$ & Solvent evaporation method \\
7. & KM1 & Mefenamic acid: PVP K30 & $1: 1$ & Kneading method \\
8. & KM2 & Mefenamic acid: PVP K30 & $1: 2$ & Kneading method \\
9. & KM3 & Mefenamic acid: PVP K30 & $1: 3$ & Kneading method \\
10. & KM4 & Mefenamic acid: PEG 4000 & $1: 1$ & Kneading method \\
11. & KM5 & Mefenamic acid: PEG 4000 & $1: 2$ & Kneading method \\
12. & KM6 & Mefenamic acid: PEG 4000 & $1: 3$ & Kneading method \\
\hline
\end{tabular}

TABLE 2: MICROMERITIC EVALUATION OF MEFENAMIC ACID SOLID DISPERSION.

\begin{tabular}{|l|l|l|l|l|l|l|}
\hline S.No & Formula code & $\begin{array}{l}\text { Bulk } \\
\text { density }(\mathbf{g m} / \mathbf{m l}) \\
\mathbf{\pm} \text { SD }\end{array}$ & $\begin{array}{l}\text { Tapped } \\
\text { density }(\mathbf{g m} / \mathbf{m l}) \\
\mathbf{\pm S D}\end{array}$ & $\begin{array}{l}\text { Carr's } \\
\text { index }\end{array}$ & $\begin{array}{l}\text { Hausner } \\
\text { ratio }\end{array}$ & $\begin{array}{l}\text { Angle of } \\
\text { repose }\end{array}$ \\
\hline 1. & SEM1(1:1) & $0.4117 \pm 0.03$ & $0.6363 \pm 0.03$ & $35.29 \%$ & 1.5455 & $21^{0} 81^{1}$ \\
2. & SEM2(1:2) & $0.5135 \pm 0$ & $0.6785 \pm 0.06$ & $24.31 \%$ & 1.3213 & $23^{0} 49^{1}$ \\
3. & SEM3(1:3) & $0.5178 \pm 0.03$ & $0.7073 \pm 0.04$ & $26.79 \%$ & 1.3659 & $23^{0} 72^{1}$ \\
\hline
\end{tabular}


Gomathi et al., World J Pharm Sci 2021; 9(9): 160-169

\begin{tabular}{|lllllll|}
\hline 4. & SEM4(1:1) & $0.3846 \pm 0.04$ & $0.5 \pm 0$ & $23.08 \%$ & 1.300 & $22^{0} 05^{1}$ \\
5. & SEM5(1:2) & $0.4318 \pm 0.02$ & $0.4871 \pm 0$ & $11.35 \%$ & 1.1280 & $23^{0} 44^{1}$ \\
6. & SEM6(1:3) & $0.4166 \pm 0.04$ & $0.4761 \pm 0$ & $12.49 \%$ & 1.1428 & $26^{0} 28^{1}$ \\
7. & KM1(1:1) & $0.4210 \pm 0.02$ & $0.5 \pm 0.03$ & $15.8 \%$ & 1.1876 & $21^{0} 47^{1}$ \\
8. & KM2(1:2) & $0.4545 \pm 0$ & $0.4838 \pm 0.03$ & $6.056 \%$ & 1.0644 & $22^{0} 68^{1}$ \\
9. & KM3(1:3) & $0.4615 \pm 0.06$ & $0.5454 \pm 0.03$ & $15.38 \%$ & 1.1818 & $23^{0} 62^{1}$ \\
10. & KM4(1:1) & $0.32 \pm 0.08$ & $0.3809 \pm 0.05$ & $15.98 \%$ & 1.1903 & $19^{0} 70^{1}$ \\
11. & KM5(1:2) & $0.3658 \pm 0.02$ & $0.5 \pm 0.04$ & $26.84 \%$ & 1.3668 & $24^{0} 88^{1}$ \\
12. & KM6(1:3) & $0.3393 \pm 0.04$ & $0.4130 \pm 0.03$ & $17.84 \%$ & 1.2172 & $29^{0} 42^{1}$ \\
\hline
\end{tabular}

TABLE 3. RESULTS OF \%PRACTICAL YIELD AND DRUG CONTENT.

\begin{tabular}{|l|l|l|l|}
\hline S. No & Formula Code & $\begin{array}{l}\text { \%Practical } \\
\text { Yield } \pm \text { SD }\end{array}$ & $\begin{array}{l}\text { \%Drug Content } \\
\pm \text { SD }\end{array}$ \\
\hline & & & \\
1. & SEM1(1:1) & $95 \pm 0.02$ & $97.17 \pm 0.04$ \\
2. & SEM2(1:2) & $90 \pm 0.09$ & $97.44 \pm 0.03$ \\
3. & SEM3(1:3) & $87.5 \pm 0.04$ & $96.15 \pm 0.03$ \\
4. & SEM4(1:1) & $95 \pm 0.04$ & $96.66 \pm 0$ \\
5. & SEM5(1:2) & $96.6 \pm 0.05$ & $97.69 \pm 0.05$ \\
6. & SEM6(1:3) & $92.5 \pm 0.05$ & $96.66 \pm 0.05$ \\
7. & KM1(1:1) & $90 \pm 0.02$ & $96.92 \pm 0.04$ \\
8. & KM2(1:2) & $93.3 \pm 0.04$ & $95.89 \pm 0.03$ \\
9. & KM3(1:3) & $90 \pm 0.04$ & $98.46 \pm 0.03$ \\
10. & KM4(1:1) & $85 \pm 0.04$ & $95.12 \pm 0$ \\
11. & KM5(1:2) & $86.6 \pm 0.05$ & $95.64 \pm 0$ \\
12. & KM6(1:3) & $87.5 \pm 0.05$ & $98.46 \pm 0.02$ \\
\hline
\end{tabular}

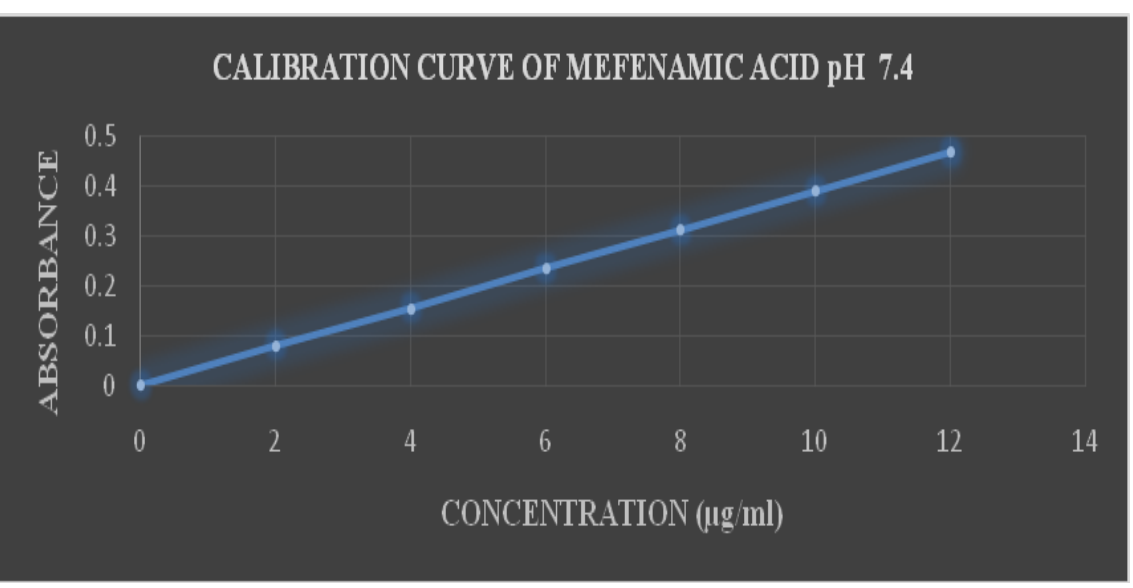

Figure 1. Calibration curve of Mefenamic acid. 
a).

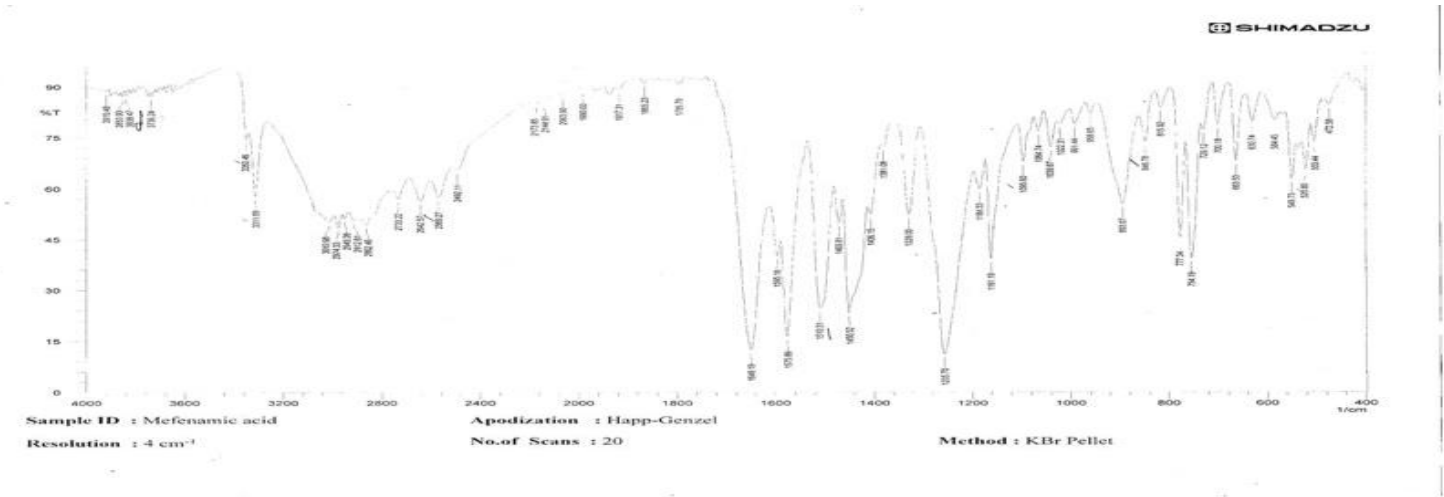

b).

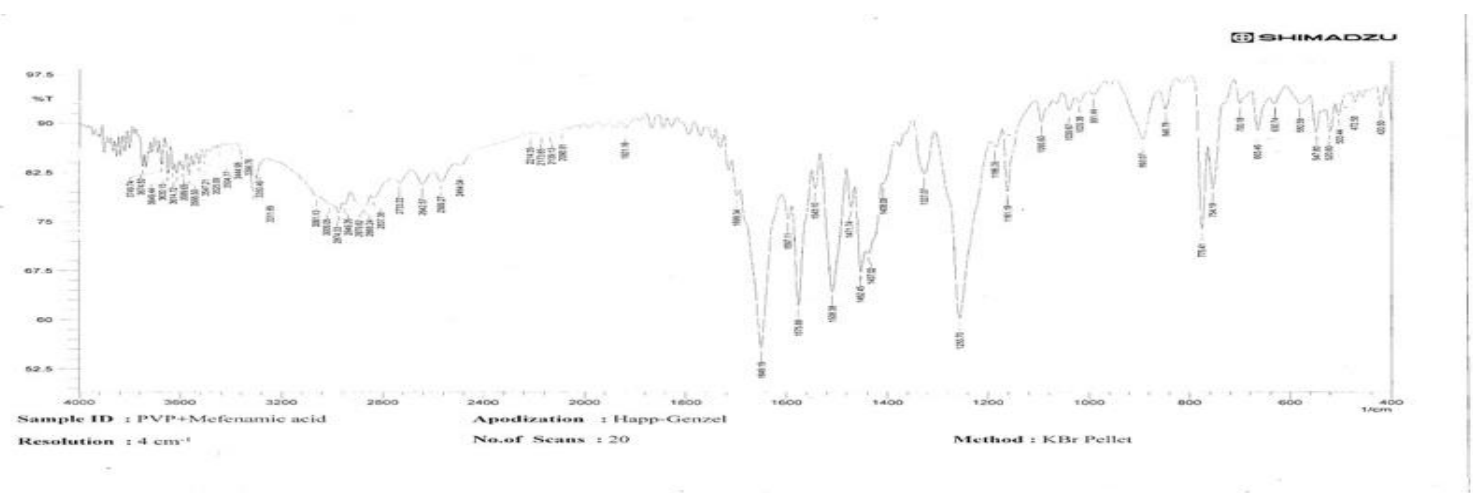

c).

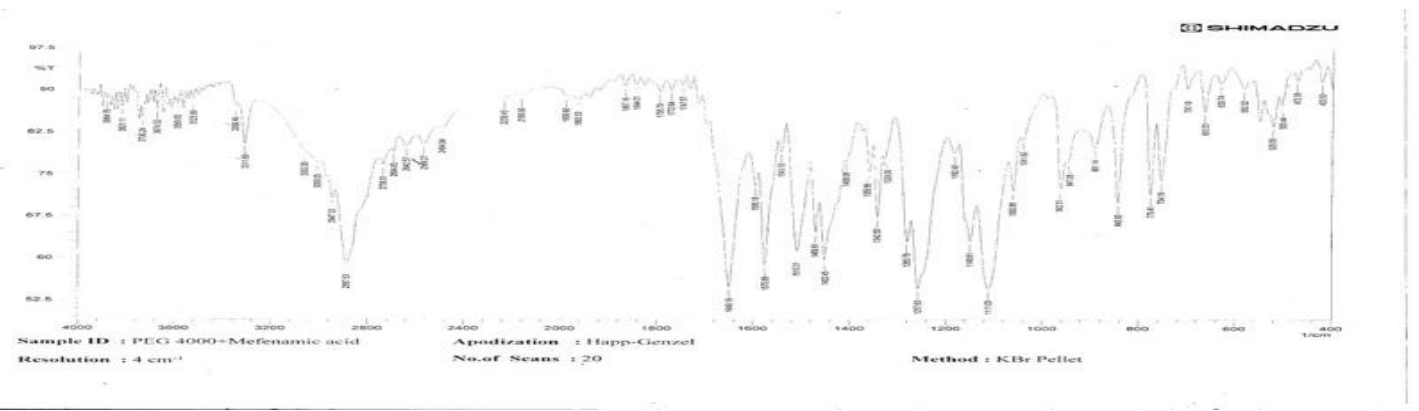

Figure 2. FTIR Spectrum of a).Mefenamic acid (pure drug) b). Mefenamic acid + PVP K 30 c). Mefenamic acid + PEG 4000 
Gomathi et al., World J Pharm Sci 2021; 9(9): 160-169
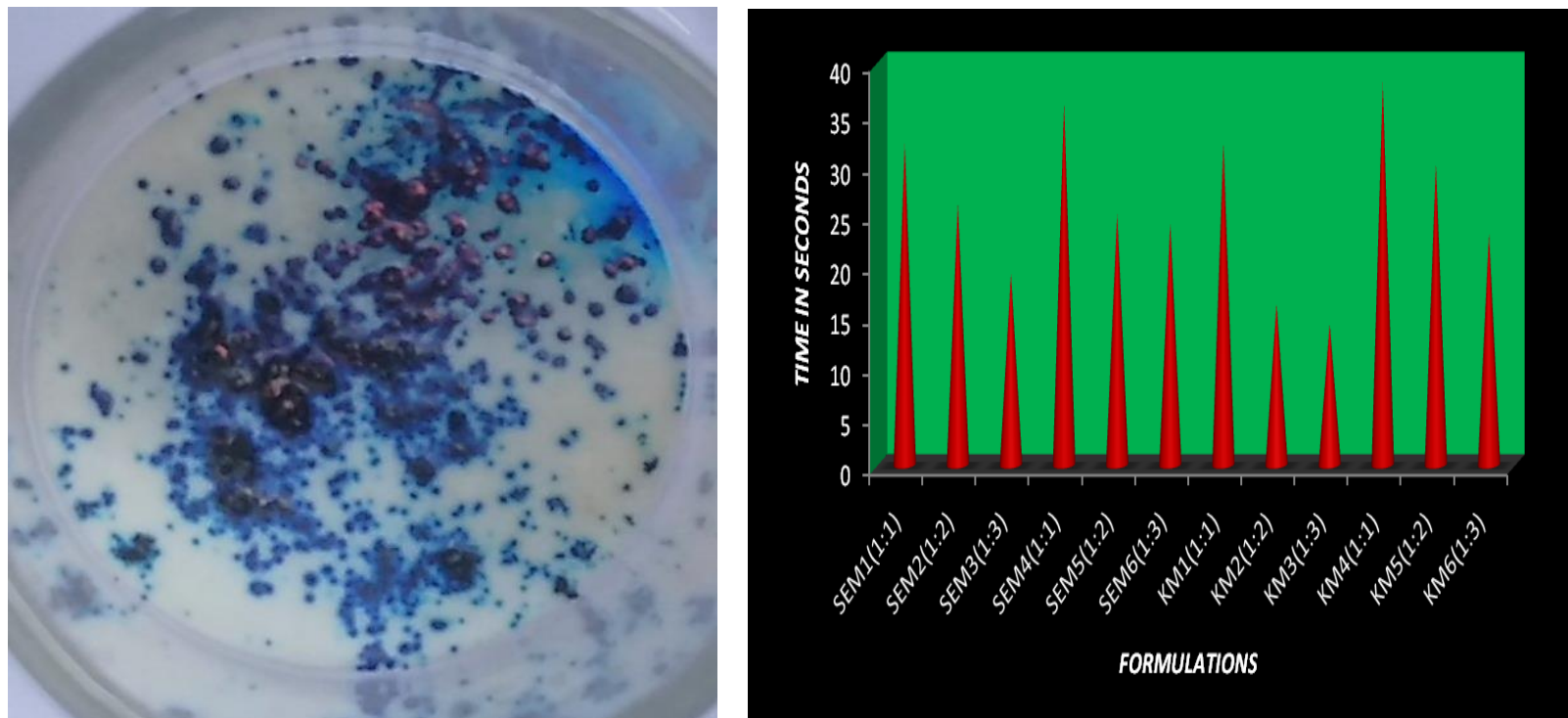

Figure 3. Comparison of wettability of solid dispersions of Mefenamic acid.

a) PVP K 30

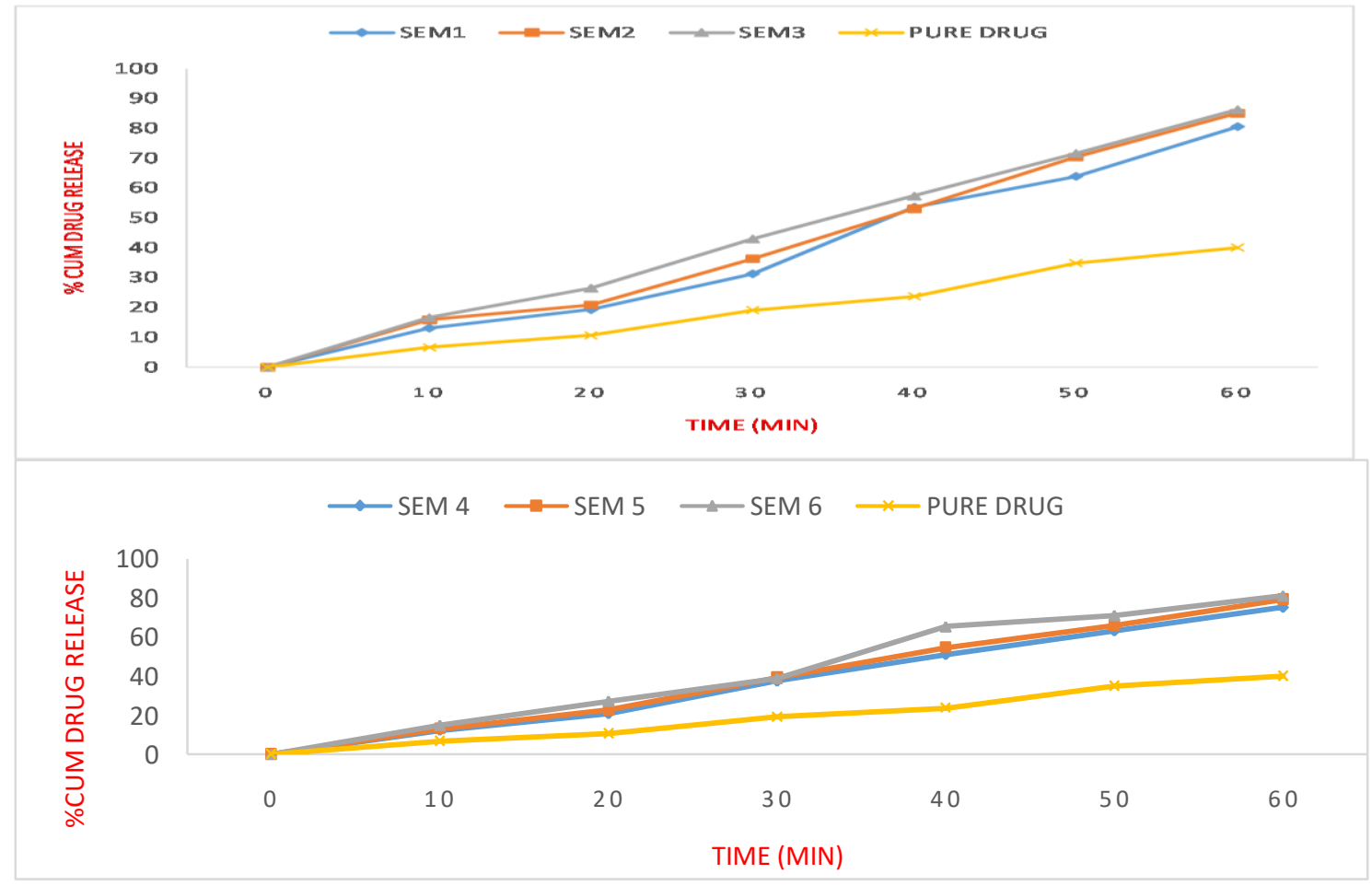

c) PVP K 30 


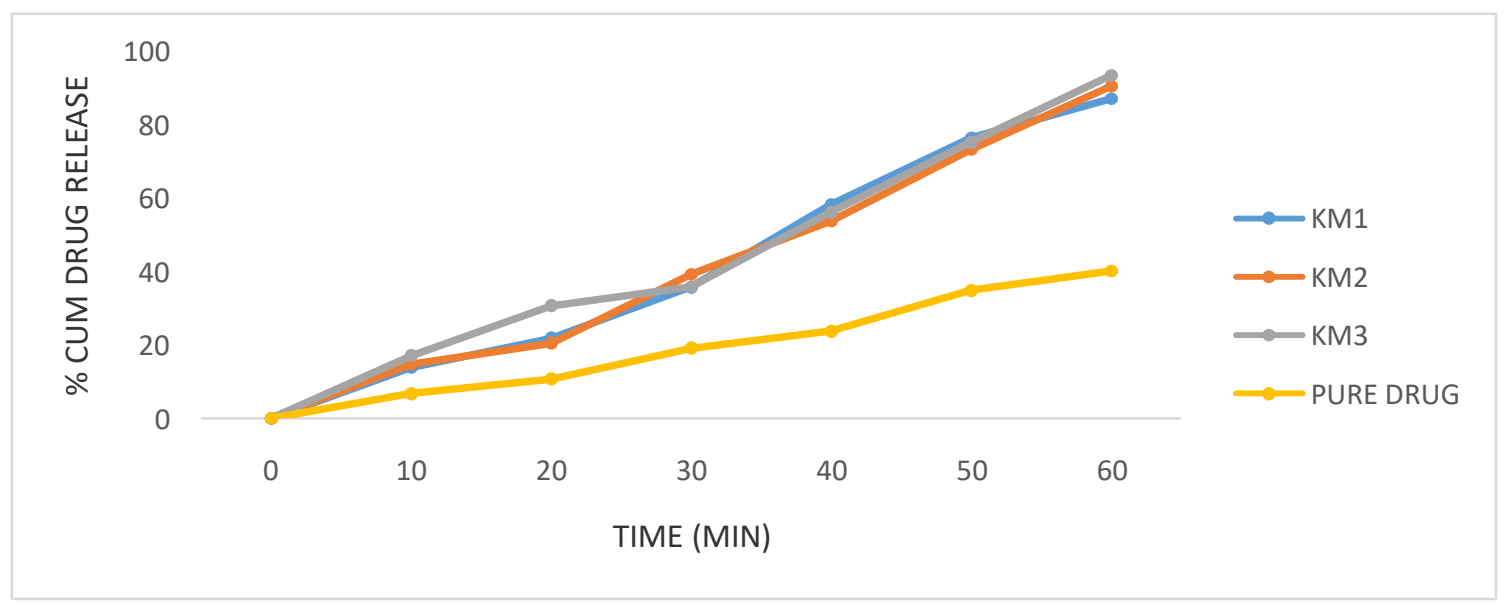

\section{d) PEG 4000}

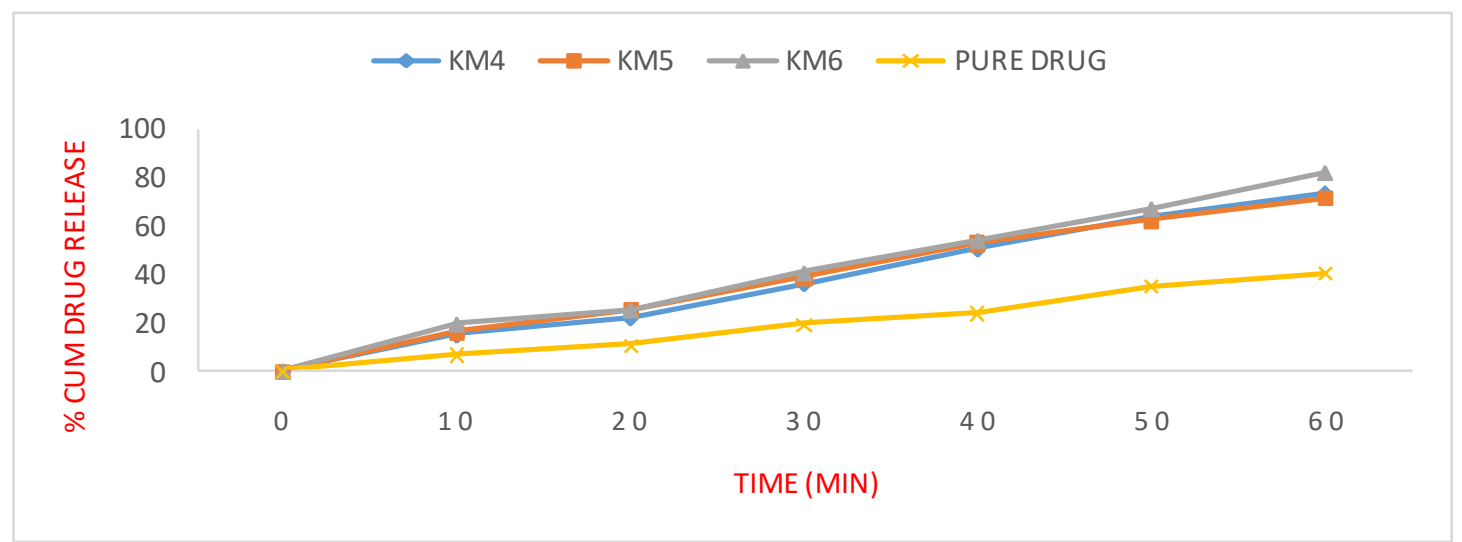

e) PVP K 30

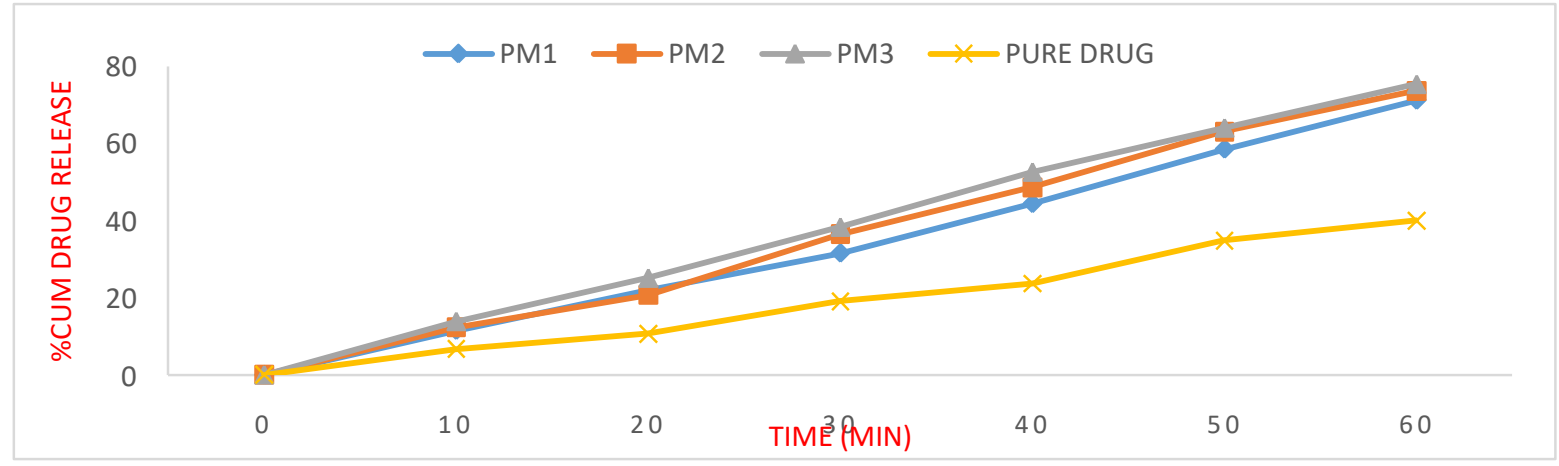

f) PEG 4000 


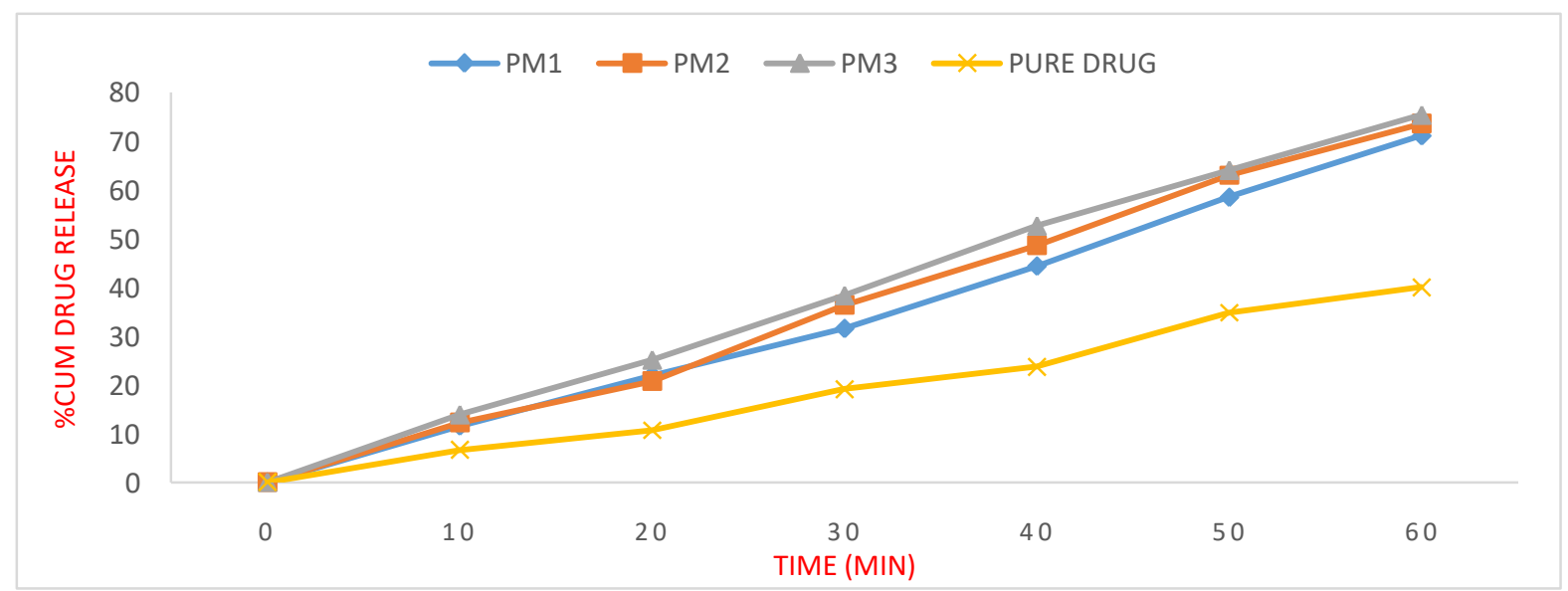

Figure 4. In vitro dissolution profile of Mefenamic acid Solid dispersion and Physical Mixtures(PM) .

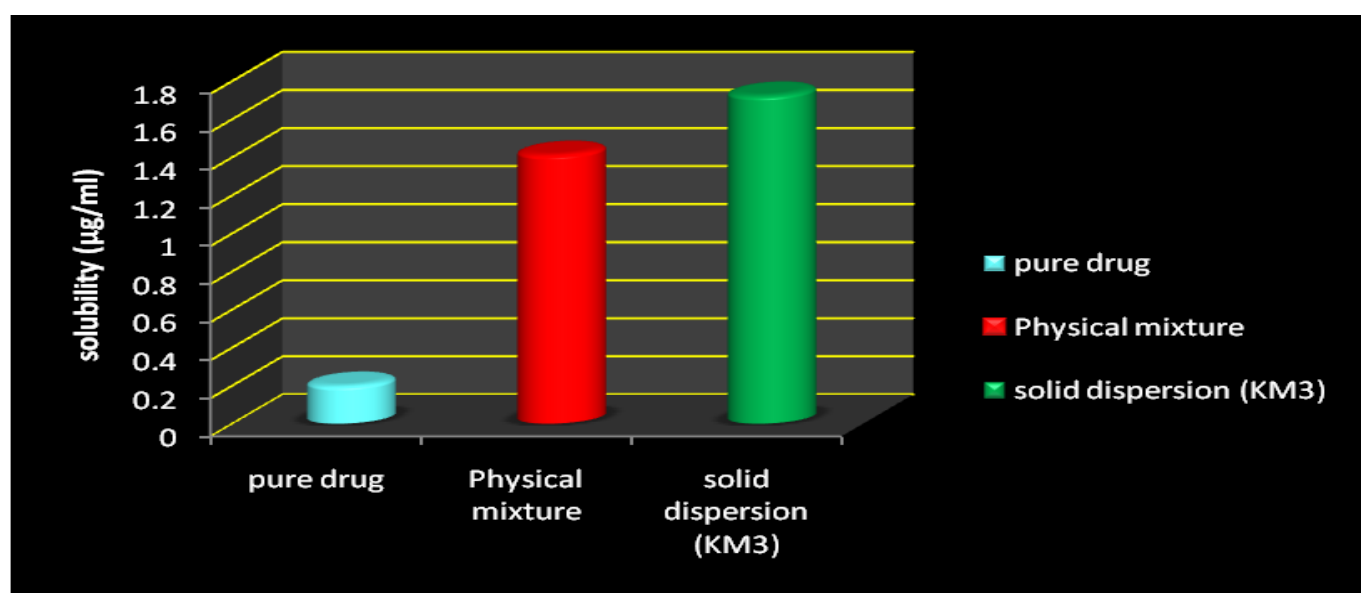

Figure 5-Solubility Study of Mefenamic acid in Phosphate Buffer pH7.4

\section{REFERENCES}

1. Lewis S et al. Solid dispersions A Review. Pak J Pharm Sci 2009; 22(2): 234-246.

2. Aruna Rawat, SurenderVerma. Solid dispersion a strategy for solubility enhancement. Int J Pharm Tech 2011; 3(2):1062-1099.

3. Singh Jaskirat et al. Solubility enhancement by solid dispersion method. J Drug Del Therap 2013; 3:148-155.

4. Abdul HasanSathali A, Kavitha R. Enhancement of solubility of Repaglinide by Solid dispersion technique. Int J Chem Sci 2012; 10(1): 377-390.

5. Irin Dewan et al. Formulation and evaluation of solid dispersions of Carvedilol a poorly water Soluble drug by using different polymer. Int Res J Pharm chem 2012; 2(3): 585-593.

6. RabiNarayan Panigrah et al. Formulation and evaluation of Indomethacin solid dispersion by using Hydrophilic Polymers. Int Res J Pharm and Health Sci 2014;2 (1): 87-957.

7. Venkateskumar krisnamoorthy et al. Characterization of Olanzapine solid dispersion. Int Res J Pharm 2011;10(1):13-23.

8. Abdul Hasan Sathali A, Selvaraj V. Enhancement of solubility and dissolution rate of Racecadotril by solid dispersion methods J Curr Chem Pharm Sci 2012;3(2):123-134.

9. Abdul Hasan Sathali A, Jayalakshmi J. Enhancement of solubility and dissolution rate of Olmesartan medoxomil by solid dispersion technique. J Curr Chem Pharm Sci. 2013; 2(3):209-225

10. Ankit Gupta, Mahesh Kumar Katarla. Formulation and evaluation of solid dispersion of Glipizide. Int $\mathbf{J}$ Pharm Drug Analysis 2014; 2(2): 74-87.

11. Shobitkumar et al. Dissolution rate enhancement of Aceclofenac by solid dispersion. Asian J Pharm life sci 2011;1 (4): 396-400.

12. James W, Pharmaceutical preformulation, the physicochemical properties of drug substances: Aulton ME. Pharmaceutics the science of dosage form design, Churchill Livingstone, Spain, 2006; pp113-138. 
13. Ramana B V et al. Dissolution rate enhancement of Aceclofenac by Solid dispersion Technique. Sch Acad J Pharm. 2013; 2: 113-118.

14. Santhosh R Iyer, Sivakumar R. Formulation and evaluation of fast dissolving tablets of Risperidone solid dispersion.Int J Pharm Chem Bio Sci 2013; 3: 388-397.

15. Kulkarni parthasarathikeshavrao et al. Preparation and evaluation of Naproxen solid dispersion by various technique. Int Res J Pharm 2012; 3(9) 174-177

16. Mogal SA et al. Solid dispersion technique for improving solubility of some poorly soluble drugs Der Pharma Lettre. 2012; 4: 1574- 1586.

17. Venkateskumar krisnamoorthy et al. Characterization of olanzapine solid dispersion. Int Res J Pharm.2011: 10(1). 13-23

18. Shivalingam MR et al. Preparation and evaluation of solid dispersion of Glipizide. Int J Pharm Res Dev 2013;3(1). 231-239

19. Sucheta Bhise, Dyandevi Mathure. Solubility enhancement of antihypertensive agent by solid dispersion technique. Int.J of Pharm \& Life Sci. 2011; 2(8); 970-975. 